\title{
D epois da escola, o encontro é no shopping: Sociabilidades, conectividade e jovens surdos em Porto Alegre (RS)
}

Marta Campos de Quadros ${ }^{1}$

\section{Resumo}

Esse artigo é um recorte de pesquisa de pós-doutoramento em desenvolvimento cujo objetivo é (re)conhecer e compreender as redes de sociabilidade de jovens surdos e as relações estabelecidas com os espaços de lazer e com uma cultura urbana marcada pela conectividade na construção de identidades e culturas juvenis surdas. Inscrita nos Estudos Culturais e nos Estudos Surdos, adota a etnografia pós-moderna como ferramenta teórico-metodológica e Porto Alegre (RS) como campo para a observação. Palavras-Chaves: Estudos Culturais. Estudos Surdos. Juventudes. Cultura Urbana. Conectividade.

\section{After School, the M eeting is In the M all: Sociabilities, Connectivity and D eaf Youths in Porto Alegre (RS)}

\section{Abstract}

This article is part of a in progress post-doc research whose goal is to recognize and understand the sociability networks of young deaf people and the relationships which can be established with

${ }^{1}$ Doutora em Educação, bolsista de pós-doutoramento CAPES-REUNI junto à Faculdade de Educação da UFRGS, PPGEdu. Pesquisadora associada ao Núcleo de Estudos de Currículo, Cultura e Sociedade (NECCSO/UFRGS) e ao Grupo de Pesquisa SINAIS: sujeitos, inclusão, narrativas, identidades e subjetividades -CNPq. 
leisure spaces and an urban culture characterized by connectivity in the construction of the youth deaf identities and cultures. It is entered in Cultural Studies and Deaf Studies and adopts the postmodern ethnography as theoretical and methodological tool and Porto Alegre (RS) as a field for the observation.

Key-words: Cultural Studies. Deaf Studies. Youths. Urban Culture. Conectivity.

\section{Reconhecendo possibilidades}

Ivete Sangalo entra no palco do Planeta Atlântida. Garotos e garotas começam a pular e a gritar. Tal cena tem se repetido nos últimos dois anos, a cada apresentação da cantora no festival de música gaúcho. Próximo a mim, um garoto gesticula rápida e entusiasmadamente. A garota que está com ele responde também com gestos. Um terceiro garoto observa e, logo depois, entra na conversa. Identifico a utilização da língua de sinais entre eles e me pergunto quais motivos levam garotos surdos a participarem daquele tipo de festa. Que relações estabelecem com os outros jovens que frequentam estes lugares? (Excerto do Diário de Campo, fev. 2009)

[...] A esta hora, final de tarde de sábado, as tribos juvenis se misturam na praça de alimentação do Bourbon Country, shopping center na zona leste de Porto Alegre. Depois de mais de três meses observando os jovens e suas práticas de escuta neste local, sinto um movimento diferente. Perto de uma sanduicheria localizo a razão daquele 'barulho', já meu conhecido dos tempos de ULBRA. Um grupo grande de jovens surdos conversa animadamente. Percebo que os olhares interessados são diferentes daqueles observados nos grupos de jovens ouvintes. Eles não se desviam das mãos e da face do interlocutor. Riem, brincam, parecem estar contando piadas. Fazem barulho! Não fosse este 'detalhe', seria muito provável que o passante desavisado os identificasse com os jovens ouvintes que por ali circulam: roupas, adereços, lanches...os marcadores juvenis parecem os mesmos. [...] (Excerto do Diário de Campo, abr. 2011) 
Escolhi estes dois excertos dos diários de campo de minha pesquisa de doutorado (Quadros, 2011), recentemente concluída, para iniciar este artigo por estarem relacionados às cenas cotidianas com as quais venho me deparando há seis anos (2007/2012) ao percorrer as ruas e outros tantos lugares que conformam a cidade de Porto Alegre, capital do Rio Grande do Sul, em seus múltiplos tempos e espaços, através das práticas cotidianas dos seus 1,4 milhão de habitantes (IBGE, 2011) e outros tantos 'transeuntes'. Entre as muitas situações que se repetiram com ligeiras variações enquanto meu olhar capturou a presença dos garotos e garotas com seus artefatos sonoros portáteis e os significados a eles atribuídos como marcadores identitários através de suas práticas culturais de escuta, estavam aquelas situações em que os 'outros' jovens - negros, índios, cegos, surdos, homossexuais, por exemplo - também eram capturados. Muito frequentemente me perguntava e ainda me pergunto sobre quem são e como são estes jovens que, diariamente, entram, circulam, se relacionam entre si, e saem das nossas escolas e de muitos outros lugares. Como se relacionam entre si e com uma cultura marcada pela tecnologia e conectividade? Por quais lugares transitam? O que fazem em suas horas de lazer, no seu tempo livre?

Tais questões sobre outras e diferentes práticas culturais envolvendo a escuta, ou a ausência, ou a impossibilidade da mesma, não são recentes. Há algum tempo me questiono sobre a forma como as pessoas, principalmente os jovens, se relacionam com artefatos e produtos sonoros - que tipo de artefatos adquirem e a partir da 'indicação' de quem (mídia, amigos, família?); onde os utilizam; o que ouvem, que significados atribuem a eles na sua vida cotidiana - e como estas relações podem de alguma forma estar articuladas com a produção de uma certa 'juventude', representada na mídia e em muitos outros lugares da cultura, como "sempre conectada".

Nos últimos anos, também tenho constatado mudanças na sala de aula universitária: estudantes de outros países e suas cultu- 
ras estão presentes em diálogo com o que nós, os 'da casa', trazemos com as nossas presenças; a presença cada vez mais explícita de estudantes que assumem cotidianamente a sua homossexualidade; o discurso militante de estudantes de diferentes etnias relativo às relações étnico-raciais no sentido de reivindicar no espaço escolar o respeito ao seu direito de ser diferente. Uma presença, contudo, tem me inquietado mais intensamente, a presença dos estudantes surdos e dos intérpretes de língua brasileira de sinais - me sentia e me sinto interpelada por estes novos atores que passam a integrar a cena da sala de aula universitária. Seus gestos, seus modos de olhar, suas formas de relacionamento, suas maneiras de se comunicar e de interagir, muitas vezes, 'roubam' a minha atenção, fazendo com que me ausente daquele 'aqui e agora' de aluna/professora ouvinte. Lembro-me da dificuldade de me comunicar com o primeiro aluno surdo que frequentou uma das disciplinas lecionadas por mim, em 2002, em um curso de Comunicação Social - Jornalismo. Eu não sabia sinalizar e ele não fazia leitura labial.

Foi, então, percorrendo este caminho que a possibilidade de pesquisa se desenhou e vem tomando forma através do projeto Jovens Surdos, Redes de Sociabilidade e Espaços de Lazer na Metrópole Comunicacional, uma agenda para a educação. 0 objetivo de tal investigação é (re)conhecer e compreender as redes de sociabilidade de jovens surdos e as relações que possam ser estabelecidas com os espaços de lazer e com uma cultura urbana marcada pela conectividade na construção de identidades e culturas juvenis.

Através do presente artigo busco mostrar as primeiras aproximações de uma pesquisadora ouvinte que, inscrita nos Estudo Culturais ${ }^{2}$, por quase três décadas esteve 'escutando' ouvintes, e que agora, tal qual estrangeira busca 'olhar' o mundo surdo, ca-

${ }^{2}$ Os Estudos Culturais não se configuraram como uma disciplina, ao contrário, são multi- interdisciplinares, e colocam em articulação diferentes disciplinas e conceitos visando a análise de aspectos culturais da sociedade e das relações de poder que podem neles estar envolvidas. 
racterizado, conforme Skliar (2012) pela surdez como uma diferença a ser politicamente reconhecida; uma determinada experiência visual que inclui uma língua gestual visual como natural, uma identidade múltipla ou multifacetada e localizada dentro do discurso sobre a 'deficiência', mas não da 'falta'.

\section{N em o mesmo, nem o outro: a dupla singularidade do juvenil e da surdez}

Neste sentido, parafraseando o título de um texto publicado por Serrano (2002) no qual indaga sobre a singularidade do 'juvenil', ou o que o diferenciaria de outras formas de subjetividade e o que definiria o específico desta condição, me aproximo dos Estudos Surdos ${ }^{3}$, procurando construir uma articulação possível com estudos sobre o juvenil, notadamente mais concentrados na sociologia e na antropologia das juventudes. É desta forma, como sugerem Magnani, Silva e Teixeira (2008), que experimento 'olhar de perto e de dentro', mesmo ainda sem o domínio da língua brasileira de sinais (libras), língua nativa do povo surdo, e sem um conhecimento mais aprofundado do que vem sendo chamado de 'cultura surda', para uma dupla singularidade: o juvenil e a surdez. Dito de outra maneira, experimento olhar para os modos de ser jovem surdo no âmbito da cultura urbana contemporânea.

Conforme Serrano (2002), 'ser jovem', nomear-se ou ser nomeado como 'jovem' constitui um ato discursivo com complexas implicações, uma vez que pressupõe a forma como se organizam biografias individuais, formas de interação e socialização, estilos de vida, organização das formas como as diferentes so-

${ }^{3}$ Os Estudos Surdos constituem-se um campo de saberes e entende a surdez, não como deficiência ou experiência de uma falta, mas como uma diferença e uma experiência visual. Os Estudos Surdos se articulam com os Estudos Culturais buscando um horizonte epistemológico no qual a surdez passa a ser reconhecida como uma questão de diferença política, de experiência visual, de identidades múltiplas, um território de representações diversas que se relaciona com, mas não se refere aos discursos sobre a deficiência. (Skliar, 2012) 
ciedades distribuem recursos materiais e simbólicos, bem como relações de poder, entre outros aspectos. Neste sentido, o autor chama a atenção para o fato dos estudos que estão sendo desenvolvidos historicamente sobre a juventude, o juvenil, os jovens e as jovens e suas culturas, bem como os discursos midiáticos em circulação e as 'tímidas' políticas públicas formuladas, terem como eixo central de normalidade uma determinada adultez e posicionarem os jovens e suas culturas ou como a reprodução de um 'mesmo' desejável, ou como um 'outro', diferente, excêntrico (fora do centro), mas de qualquer forma desde uma perspectiva adultocêntrica. Para Serrano (2002) perguntar pela singularidade do juvenil, implica "mobilizar formas de vermos uns aos outros, questionar os lugares desde os quais nos nomeamos uns aos outros, desestabilizar posições aparentemente fixas, mas não por isso, menos frágeis" (Serrano, 2002, p. 11)

Da mesma forma, Padden e Humphries (1998) questionam as formas como os surdos têm sido narrados nos estudos desenvolvidos, nos discursos em circulação através das produções midiáticas, e nas diferentes políticas públicas. Na concepção destes e de outros autores inscritos nos Estudos Surdos, nomear-se e ser nomeado 'surdo' implica diferentes enquadramentos e posições de sujeito. Dizer-se e dizer que alguém é 'surdo' é um ato discursivo com efeitos complexos sobre a singularidade da 'surdez', ou o que a diferenciaria de outras formas de subjetividade e o que definiria a especificidade desta condição. Dentro da perspectiva ouvintista, ainda considerada hegemônica, ou seja, a partir de um conjunto de representações colocadas em circulação tendo como referência os ouvintes/a audição, nas quais o surdo é posicionado e se posiciona como um ouvinte que é privado fisicamente da audição, produzem-se "as percepções do ser deficiente, do ser ouvinte; percepções que legitimam as práticas terapêuticas habituais" (Skliar, 2012, p. 15) que buscam

\footnotetext{
${ }^{4}$ As traduções de obras referidas em suas línguas de origem sem tradução para a língua portuguesa são de responsabilidade da autora.
} 
incessantemente 'corrigir' a surdez e devolver ao 'surdo' a sua pressuposta normalidade, a 'audição'.

Assim, desde o ouvintismo, os discursos sobre o surdo e a surdez têm como eixo central de normalidade o ouvinte/ a audição e, neste sentido, o surdo e suas culturas são posicionados, tal qual o jovem na perspectiva adultocêntrica, ou a partir de uma determinada audição 'desejada' como o 'mesmo', aquele que 'pode' ouvir, ou como um 'outro', diferente, excêntrico (fora do centro), deficiente, mas de qualquer forma em uma perspectiva audiocêntrica.

Padden e Humphries (1998), pensando a singularidade da surdez e das culturas surdas, argumentam a necessidade de posicioná-las a partir de um eixo diferente da audição e defendem que se coloque a surdez como eixo central de normalidade para buscar compreendê-las. Wrigley (1996) a partir de estudos realizados na Tailândia, centrados nas circunstâncias e no posicionamento da língua tailandesa de sinais, tendo como base as experiências da comunidade surda, propõe que se pense a surdez, não como uma questão de audiologia, mas ao nível epistemológico, não excluindo a existência de representações que posicionem a surdez como uma privação sensorial que faz com que os sujeitos surdos experimentem uma vida e um mundo caracterizados por uma falta, por uma ausência da audição. Entretanto, tal autor argumenta a necessidade de se analisar as relações entre conhecimento e poder, incluindo "representações sobre a surdez como deficiência auditiva e como construção visual que nos obriga a conduzir nossa reflexão numa dimensão especificamente política" (Skliar, 2012, p. 10).

É nesta perspectiva que buscamos mostrar e compreender, aqui de forma ainda inicial, uma determinada juventude surda urbana que circula pela cidade de Porto Alegre e, a partir de suas práticas culturais e trânsitos, reconhecer suas redes de sociabilidade, conectividade e espaços de lazer através da etnografia pós-moderna como ferramenta teórico-metodológica. Esclareço 
que adoto tal ferramenta na direção apontada por Geertz (1989), Geertz e Clifford (1992), Appadurai (2005), Gottschalk (1998) entre outros autores que, pensando as transformações decorrentes de um processo de autoquestionamento no âmbito da antropologia (urbana), relativas às práticas etnográficas, enfatizam a premência de mudanças. Apoiados principalmente no fato de que as populações e os lugares que antes os etnógrafos pesquisavam passaram por profundas transformações, assumindo uma feição completamente nova, estes autores argumentam que os trânsitos populacionais através do turismo, da circulação urbana, ou das migrações, muitas vezes vinculadas aos fluxos do capital, criam outras realidades mais complexas para serem observadas por um pesquisador que, necessariamente, não 'vai mais a campo', mas 'vive e experimenta' cotidianamente de dentro este mesmo campo, situação da qual me aproximo na pesquisa em questão.

Antes de seguir adiante, aclaro também que, mesmo conhecendo as discussões sobre cultura, identidade e comunidade surda efetivadas por Perlin (2004, 2012), Karnopp, Klein e Lunardi-Lazzarin (2011), Bauman (2007), Holcomb, Holcomb, e Holcomb (1994), Kannapell (1994), Ladd, (2003), Lane, Hoffmeister, e Bahan (1996), Lopes e Veiga-Neto (2006) entre outros pesquisadores, aqui não me detenho nas mesmas. Centro meu olhar nas práticas culturais juvenis, considerando, conforme Strobel (2009), a cultura surda como uma forma peculiar do sujeito surdo entender o mundo e de modificá-lo com o objetivo de torná-lo acessível e habitável, ajustando-o às suas percepções visuais, que contribuem para a definição das identidades e das comunidades surdas, incluindo-se a língua, as ideias, as crenças, os costumes e os hábitos do povo surdo. Tal cultura é transmitida através do compartilhamento com outros surdos em redes de sociabilidade específicas que incluem: associações e organizações, frequência a determinadas escolas e locais de prática desportivas, igrejas, entre outros lugares e grupos. 
Perlin (2004) acrescenta que a cultura surda, assim como outras formas de cultura, é também um processo discursivo que através da linguagem engendra identidades em um campo de lutas por significados produzidos e articulados em meio a relações de poder. Sobre as identidades surdas, a autora (Perlin, 2012) lembra que as mesmas são produzidas no interior de representações possíveis da cultura surda e se moldam de acordo com a maior ou menor receptividade cultural assumida pela pessoa surda. Identidades e alteridades são inseparáveis no âmbito da cultura, pois os processos de produção das representações que forjam as identidades, múltiplas, móveis, flexíveis, híbridas, incompletas; produzem da mesma forma as diferenças de forma sempre relacional, considerando-se um determinado tempo e espaço, portanto, historicizadas (Hall, 1999, 2005).

Especificamente sobre a comunidade (surda), Magnani, Silva e Teixeira (2008) comentam que esta é uma categoria que se faz presente frequentemente nos textos e discursos das pessoas surdas, bem como dos estudiosos que abordam este tópico. Contudo, os autores, tomando como referência os significados clássicos de 'comunidade' e a experiência vivida pelos surdos, sublinham uma primeira peculiaridade relativamente à 'comunidade surda': a ausência de um território contínuo. Este aspecto é comentado por Wrigley (1996, p.13) quando afirma que a surdez é um grande e democrático 'país' sem um 'lugar' próprio cuja 'cidadania' não tem uma origem geográfica, mas se constitui a partir do compartilhamento cultural e linguístico e atravessa todas as fronteiras de classe, gênero ou raça, sendo mais do que uma simples condição. Assim ainda que a tendência seja enquadrar as pessoas surdas sob um mesmo 'rótulo' ou 'etiqueta', a surdez é uma construção cultural de característica plural na qual convivem surdos oralizados, surdos implantados, surdos filhos de pais surdos, surdos filhos de pais ouvintes, surdos falantes nativos de língua de sinais, não surdos que utilizam língua de sinais, intérpretes, surdos negros, surdos homossexuais, mulheres surdas, homens surdos, jovens surdos... 
Magnani, Silva e Teixeira (2008) consideram que, no caso dos surdos da cidade de São Paulo, levando em consideração o foco analítico nas redes de sociabilidade dos mesmos, é possível afirmar que os surdos se utilizam de um pressuposto linguístico para construírem uma noção de comunidade: o compartilhamento da língua brasileira de sinais reconhecida no Brasil como direito humano inalienável e como língua oficial dos surdos, através da Lei Federal 10.436 de 24/04/2002, regulamentada pelo Decreto Federal 5.626 de 22/12/2005. Os mesmos autores ainda explicitam que se é possível identificar uma referência territorial para a comunidade surda, esta "ocorre por meio da apropriação de determinados espaços da cidade" (Magnani, Silva e Teixeira, 2008, p. 60).

Após (re)conhecer alguns aspectos que singularizam a surdez, volto o meu olhar para o que pode estar constituindo a singularidade de uma determinada juventude urbana e de suas culturas. Conforme Green e Bigum (2002), a juventude tem sido vivida contemporaneamente de diferentes formas e em diferentes espaços e temporalidades, fazendo com que muitas vezes nos sintamos entre alienígenas e que passemos a utilizar o termo juventude(s) no plural como forma de assinalar a sua diversidade e os marcadores culturais de diferenças. Hall $(2003,2005,1999)$ destaca o caráter fragmentário, transitório, das identidades na contemporaneidade e afirma que nossos pertencimentos estariam na ordem das posições de sujeito e dos traços identitários, considerando-se as diferenças. Da mesma forma, Feixa (2004), a partir da antropologia da juventude, reconhece a presença marcante das diferenças e argumenta sobre a exigência de buscarmos compreender os jovens a partir das culturas juvenis e não de inscrevê-los numa mesma cultura e identidade a partir dos parâmetros etários.

É ainda nas palavras de Feixa (apud Martín-Barbero, 2001) que vislumbro uma das possíveis chaves para correlacionar o que tenho observado relativamente aos jovens (surdos e não surdos) em Porto Alegre e esta característica 'territorial' da comunidade 
surda apontada por Magnani, Silva e Teixeira (2008). Segundo o autor catalão, as práticas juvenis tem tido uma relação com a cidade como um espaço privilegiado de mediação no processo de produção de suas identidades.

A emergência da juventude está se traduzindo em uma redefinição da cidade. A ação dos jovens serve para redescobrir territórios urbanos esquecidos ou marginais, e para atribuir novos significados a diversas zonas da cidade. Através da festa, das rotas do ócio, mas também do graffiti, os jovens questionam os discursos dominantes sobre a cidade. (Feixa apud Martín-Barbero, 2001, p. 233)

A cidade, então, no contexto das práticas juvenis urbanas, a partir do proposto por De Certeau (1997), está inscrita num conceito de espaço que difere da denominação física e é tomada como um local prático que não existe desde sempre, mas é constituído a partir da interação dos jovens com o tempo e as relações sociais que estabelecem. Relativamente às culturas juvenis, Garay (1996) assinala que o desenvolvimento tecnológico que propiciou a produção dos diferentes artefatos portáteis, também permitiu que os jovens se apropriassem do espaço urbano de diferentes formas, transformando os espaços 'públicos' em espaços 'privados'. A cidade como ponto de referência simbólico tem seus espaços delimitados por diferentes grupos de jovens, os quais servem como chaves para a memória coletiva dos grupos que os revestem de um valor cultural específico e são parte constitutiva das identidades juvenis.

Na mesma direção, mas buscando compreender as práticas culturais de jovens ingleses no final da década de 1980, Willis (1990) sugere a necessidade de se (re)conhecer o que de vibrante e criativo compõe a vida cotidiana, ordinária, comum, mesmo quando isto possa estar invisibilizado, desprezado, desdenhado. $\mathrm{O}$ autor argumenta que a vida de todos os dias dos jovens é "plena de expressões, sinais e símbolos através dos quais indivíduos e grupos procuram estabelecer criativamente sua presen- 
ça, identidade e significados" (Willis, 1990, p.1). Assim, é neste caráter comum, ordinário da cultura - porque disseminada por todos os lugares, resistente, forte e compartilhada - que podemos encontrar o 'extraordinário'. Em outras palavras, é no cotidiano que os jovens expressam sua significância cultural através de distintas práticas. Refletindo sobre o que denomina de trabalho e criatividade simbólica dos jovens na vida cotidiana, Willis (1990) enfatiza que há

uma multiplicidade de modos através dos quais os jovens usam, humanizam, embelezam, investem de significado seus espaços de vida e práticas sociais comuns e imediatos - estilos pessoais e escolha de roupas; seletivo e ativo uso da música, TV, revistas; decoração dos quartos; rituais de romance e estilos subculturais; o estilo, as brincadeiras e os dramas dos grupos de amizade; produção de músicas e danças. (Willis, 1990, p. 2)

Tais práticas, segundo Willis, não são triviais ou inconsequentes, pois, nas condições moderno-tardias, podem ser cruciais para a criação e manutenção de identidades individuais e de grupo, culturalmente, o que implica existência de trabalho no jogo da cultura contemporânea. Magnani (2003, 2005, 2007) em diversos estudos realizados e orientados sobre as práticas culturais e redes de sociabilidades de jovens em São Paulo também assinala esta dinâmica, propondo uma família de categorias analíticas que buscam ir além das dicotomias que cercam os binômios casa-rua, comunidade-sociedade, cultura-natureza. A exemplo da utilização que este autor faz das categorias pedaço, mancha, trajeto e circuito para reconhecer os circuitos de sociabilidade e lazer da juventude surda em São Paulo - sempre alertando que é necessário no decorrer do processo de investigação aprofundá-las, tensioná-las e problematizá-las -, penso nas mesmas como possibilidades.

Neste que considero um exercício de estranhamento/aproximação com o 'campo', busco olhar para as sucessivas idas ao 'shopping', depois da escola e antes do retorno à casa ou da caminha- 
da no parque como uma espécie de circuito, ou como Magnani (2003, s/p) propõe a descrição do "exercício de uma prática ou a oferta de determinado serviço por meio de estabelecimentos, equipamentos e espaços que não mantêm entre si uma relação de contiguidade espacial, sendo reconhecido em seu conjunto pelos usuários habituais". Magnani (2003, s/p) argumenta que o circuito designa o uso do espaço e de equipamentos urbanos possibilitando, assim, "o exercício da sociabilidade por meio de encontros, comunicação, manejo de códigos”, mas diferentemente das demais categorias, é menos dependente relativamente às relações espaciais, ainda que mantenha "igualmente, existência objetiva e observável: pode ser levantado, descrito e localizado".

Ainda seguindo o exemplo de Magnani, Silva e Teixeira (2008), sublinho o caráter precário destes que são registros e reflexões preliminares da pesquisa em andamento, momento ainda marcado pelo desconhecimento, mas que me aproximou de uma das condições ditas clássicas da pesquisa etnográfica, o estranhamento. Como afirmam estes autores (Magnani, Silva e Teixeira, 2008, p. 62), "para quem é introduzido pela primeira vez num meio que lhe é estranho, tudo é significativo, nada pode ser previamente hierarquizado numa escala de valores entre o insignificante e o relevante, tudo é digno de observação e registro". Contudo, Magnani, Silva e Teixeira nos fazem recordar que "com o tempo, esta condição vai cedendo lugar a uma maior familiaridade com o meio, situação que apresenta ganhos (e perdas) específicos, já em outras etapas da pesquisa”. É então desta forma que olho para a escola, como uma 'primeira estação' do circuito de jovens surdos em Porto Alegre.

\section{A escola é o meu mundo, mas também o mundo dos outros}

Eu frequentava as sessões de fonoaudiologia duas vezes por semana e estudava com outros pares surdos na escola "especial" [...]. Nessa escola adquiri a Língua Brasileira de Si- 
nais naturalmente e vivi uma infância muito feliz. [...] essa escola era o espaço em que me identificava com os pares surdos. [...] Com onze anos, meus pais me deram a noticia que eu iria mudar de escola e explicaram o motivo: queriam que eu tivesse um processo normal de aprendizagem. [...] Embora eu quisesse continuar na escola de surdos onde eu conhecia todos os meus colegas, não tive escolha, e iniciei a terceira série do ensino fundamental, numa nova escola [...]. Ao chegar à escola dos ouvintes, percebi um outro "mundo" que me mudou completamente. Para melhor? Não, nem para pior. Só me trouxe para um mundo de identidades "contraditórias". Esse mundo me fez ser "ouvinte" ao invés de surda, ser "deficiente" ao invés de diferente. [...]. Em toda minha vida passei por processos de construção e desconstrução da minha identidade. [...] Voltei à escola de surdos [...] porque não queria terminar meu último ano com pessoas que me viam como "deficiente". A constituição da minha identidade surda voltou a ser possível quando conversei com um amigo muito querido [...], por quem tenho meus eternos agradecimentos através da internet. Ele me trouxe de volta ao mundo dos surdos onde "recuperei" minha identidade e nesse momento me reconstruí como Surda. [destaques são meus]

A escola tem sido narrada pelos surdos como um importante lugar de constituição das identidades e de sociabilidades. Padden e Humphries (1998) enfatizam o papel central que as escolas têm junto à comunidade surda e narram que durante os períodos em que ocorreram proibições do compartilhamento de uma língua cultural de surdos em razão das decisões decorrente do Congresso Internacional de Educadores de Surdos, realizado em Milão, na Itália, em 1880, as crianças e jovens foram afastados de suas famílias, convivendo com crianças de famílias surdas e adultos surdos que trabalhavam de alguma forma na escola. Segundo os autores, era nos dormitórios das instituições de ensino e asilos, onde estudavam em regime de internato, distantes do controle estruturado das salas de aula, que as crianças surdas eram introduzidas nas formas de vida social das pessoas surdas. "No ambiente informal dos dormitórios, as crianças aprendiam não só língua de sinais, mas a cultura. Desta forma, as escolas 
tornaram-se centros de atividades das comunidades que as cercavam, preservando para a próxima geração a cultura das gerações anteriores" (Padden e Humphries, 1998, p. 6).

Da mesma forma, o excerto da carta de uma jovem aluna surda, anteriormente transcrito, demonstra tal centralidade e o papel cultural comunitário da instituição escola no que diz respeito à sociabilidade e produção de identidades juvenis surdas. Esta carta, assim como outras tantas, são narrativas de surdos e ouvintes produzidas durante a segunda edição do curso de extensão e Seminário Especial do Programa de Pós-graduação em Educação da UFRGS Memórias e narrativas na Educação de Surdos ${ }^{5}$. Em quase todas as narrativas, a escola nas suas diferentes modalidades - para ouvintes, inclusiva, 'especial' para surdos, de surdos, bilíngue, de ensino Fundamental ou Médio, ou a própria universidade - aparece como um dos espaços de aproximação e encontro das pessoas surdas.

A escola, como afirmam Lopes e Veiga-Neto (2006), tem se constituído numa espécie de território para que a comunidade surda se constitua e se mantenha como tal por afinidade, interesses comuns, continuidade das relações estabelecidas e pela convivência em um tempo e espaços comuns. "Escola e comunidade surda parecem ser conceitos e espaços que se confundem no imaginário surdo", assinalam Lopes e Veiga-Neto (2006, p. 93), enfatizando que em muitas narrativas de surdos os mesmos afirmam a preferência pela escola de surdos que é vista como "possibilidade do encontro e do movimento político por uma identidade e comunidade".

\footnotetext{
${ }^{5}$ O curso de extensão e seminário especial do Programa de Pós-graduação em Educação da UFRGS Memórias e narrativas na Educação de Surdos, em 2012, está em sua terceira edição e é desenvolvido como parte da pesquisa Língua de sinais e educação de surdos: políticas de inclusão e espaços para a diferença na Escola, pelo Grupo de Pesquisa SINAIS: sujeitos, inclusão, narrativas, identidades e subjetividades, registrado no Diretório do CNPq. Este grupo investiga temas relacionados a políticas educacionais e linguísticas para surdos, experiências docentes e formação de professores. Todos os participantes do curso/disciplina assinaram Termo de Consentimento Livre e Informado autorizando o uso de suas escritas e outros registros (Thoma; Giordani, 2012)
} 
Nas palavras da jovem surda é possível identificar tais aspectos, ela "estudava com outros pares surdos na escola "especial"[...]. Nessa escola adquiri a Língua Brasileira de Sinais naturalmente e vivi uma infância muito feliz. [...] essa escola era o espaço em que me identificava com os pares surdos". Mas a escola também é o território do outro, lugar de reafirmação da luta dos surdos pelo reconhecimento da sua identidade/diferença como ela narra ao referir-se à necessidade de mudar de escola,

Ao chegar à escola dos ouvintes, percebi um outro "mundo" que me mudou completamente. Para melhor? Não, nem para pior. Só me trouxe para um mundo de identidades "contraditórias". Esse mundo me fez ser "ouvinte" ao invés de surda, ser "deficiente" ao invés de diferente.

Um outro marcador cultural juvenil surdo que a narrativa da jovem estudante possibilita constatar é a presença das tecnologias digitais no seu cotidiano. A internet é citada como um elemento que compõe a possibilidade de comunicação dos jovens surdos no âmbito dos afetos e amizades, diferentemente dos surdos mais velhos que tinham nas reuniões das associações e clubes espaços privilegiados de sociabilidade. 0 agradecimento ao amigo que possibilitou à estudante que recuperasse a sua identidade surda está registrado 'publicamente' através da internet - "A constituição da minha identidade surda voltou a ser possível quando conversei com um amigo muito querido [...], por quem tenho meus eternos agradecimentos através da internet. Ele me trouxe de volta ao mundo dos surdos onde "recuperei" minha identidade e nesse momento me reconstruí como Surda".

Olhando especificamente para os marcadores culturais surdos e sua relação com o espaço escolar, Lopes e Veiga-Neto (2006), afirmam que as lutas geracionais são comuns a todas as culturas e que as mesmas também ocorrem no interior da cultura surda: os surdos mais velhos consideram que os jovens surdos estão desvinculados das lutas de sobrevivência da cultura surda; os surdos jovens têm erguido outras bandeiras de luta vinculadas 
à necessidade de (re)atualização permanente do movimento surdo, pois outros e novos interesses na "sociedade contemporânea, marcada pela tecnologia e pelo crescimento das relações imateriais e simbólicas, estão definindo os sujeitos e suas posições na esfera global"(Lopes;Veiga-Neto, 2006, p.88). Os jovens surdos em nível da escola, depois de terem estabelecidos direitos básicos tais como o reconhecimento da língua de sinais, buscam conquistar um ensino de melhor qualidade, escolas mais bem equipadas e conectadas que possibilitem a eles colocações melhores no mercado de trabalho e ganhos maiores.

A escola, no circuito que buscamos observar, aparece, então, como um lugar importante de compartilhamento de práticas culturais de jovens surdos comuns às culturas juvenis contemporâneas que chegam à escola e nos fazem pensar nos diálogos (im) possíveis entre os diferentes sujeitos da educação. A presença constante das tecnologias digitais na forma de acesso à internet e às redes sociais via telefones móveis e computadores portáteis apresenta-se ao mesmo tempo como facilitadora da formação de redes de sociabilidade e como 'atos perturbadores' (Chambers, 1997) que recolocam em discussão questões relativas a perturbação de limites estabelecidos socialmente entre o público e o privado, a partir de mídias móveis, naquilo que diz respeito ao espaço coletivo aqui olhado como espaço escolar, como fica evidenciada na observação de campo que transcrevo a seguir.

São 8 h30 e aguardo no corredor da faculdade que meus colegas e professora cheguem para o início da aula. É cedo e ainda tenho tempo de revisar o texto previsto para a aula de hoje. Abro a mochila tentando localizar o texto e a caneta marcador. Outros colegas também leem, conferem mensagens em seus celulares ou, com fones de ouvido plugados a estes, parecem escutar música. Uma colega surda chega, sorri e sinaliza um oi que retribuo em libras apesar de meu reduzido vocabulário. Ela senta, abre a bolsa e de lá tira o celular, começando uma intensa troca de mensagens evidenciada pelos sorrisos que lança à pequena tela do aparelho e o rápido movimento de seus dedos no teclado. 
Depois dela, outros dois colegas, também surdos chegam e repetem o mesmo 'ritual'. O rapaz utiliza o celular, a garota um tablet cor-de-rosa. Às vezes sinalizam entre si - ainda não compreendo o que dizem e fico só olhando -, mostram mensagens e vídeos postados nas várias redes sociais. Esta dinâmica se repete até a professora chegar, abrir a sala e entrarmos. Alguns colegas ouvintes e surdos desativam seus aparelhos, outros não. A aula começa e alguns celulares continuam em ação. Convivem com a dinâmica da aula que se dá em libras e em língua portuguesa. Professora e tradutora, assim como os colegas parecem estar já acostumados a esta presença e, às vezes esperam que aquele 'diálogo colateral' seja momentaneamente interrompido. (Excerto do diário de campo, 10 out. 2012)

Dayrell (2007) e Carrano (2008) entre outros autores problematizam os modos de ser de jovens que frequentam diferentes escolas. Para estes autores, juventude é construção cultural, social e histórica, e sujeita a transformações marcadas por condições imbricadas na cultura contemporânea. De acordo com esta perspectiva, as relações entre juventudes e escola não se explicam em si mesmas. A partir de uma visão ampla não focada especificamente na juventude surda, Dayrell (2007) pondera que as relações entre a educação da juventude e a escola têm sido bastante debatidas, mas acabam por cair em uma visão apocalíptica, apontando para o fracasso da instituição escolar com os diversos atores escolares culpando-se mutuamente. Carrano (2008) identifica que tal situação de mútua culpabilidade está ligada a uma situação de incomunicabilidade entre tais sujeitos escolares.

Os dois autores comentam que professores e administradores escolares tendem a rotular negativamente seus jovens alunos como desinteressados, apáticos, indisciplinados e consumistas. Os alunos, por sua vez, argumentam que o melhor momento do cotidiano escolar é o recreio, quando efetivamente vivem a escola, ou a participação em projetos extracurriculares. Para os jovens estudantes, as aulas são uma 'chatice necessária', pois não têm sentido prático, os professores são despreparados, e 
os espaços são pobres, inadequados e marcados pela ausência de meios educacionais como computadores e acesso à internet (Carrano, 2008), contrariamente a cultura de mídia e conectividade na qual estão inscritos cotidianamente.

Carrano (2008) e Dayrell (2007) entendem a escola como um espaço de sociabilidades e muitos destes problemas apontados estariam relacionados a uma "ignorância relativa da instituição escolar e de seus profissionais sobre os espaços culturais e simbólicos nos quais os jovens se encontram imersos" (Carrano, 2008, p. 183) e à necessidade de compreender as práticas e símbolos implicados na condição juvenil atual, tomada como "manifestação de um novo modo de ser jovem, expressão das mutações ocorridas nos processos de sociabilização, que coloca em questão o sistema educativo, suas ofertas e as posturas pedagógicas que lhes informam" (Dayrell, 2007, p.1107). Esta situação é narrada também pelos jovens estudantes surdos nas cartas já referidas, nas aulas da universidade e nas (ainda poucas) conversas informais mantidas em outros locais com os mesmos.

Neste sentido, tais autores propõem a partir de diferentes contextos que se faça uma mudança no eixo de reflexão: passar das instituições educativas para os sujeitos jovens e suas culturas, de forma que a escola possa ser repensada para responder aos desafios colocados pelas diferentes juventudes. Carrano (2008, p.183) alerta, contudo, para a necessidade de se considerar que “o poder de formação de sujeitos pela instituição escolar tornou-se significativamente relativizado pelas inúmeras agências e redes culturais e educativas". Destaca que, as mídias massivas, alternativas e descentralizadas, bem como o mercado de consumo e os diversos grupos de identidade se tornaram lugares de intensa produção de subjetividades juvenis.

Eu e minha colega, tradutora de libras, estamos sentadas em uma das mesas do bar da faculdade. Ainda necessito de sua ajuda para compreender sobre o que os jovens surdos conversam. Duas garotas surdas entram no bar, acomodam-se 
numa mesa próxima conversando animadamente. Parecem discutir sobre algo que discordam. Pergunto a minha colega se é possível saber do que se trata. Ela olha e esclarece que a conversa gira em torno de alguma coisa que está passando na tevê ou que acessaram no You Tube. Logo a seguir chegam mais dois jovens surdos. Um é meu colega, é um jovem surdo que usa implante coclear, mas entre os jovens surdos comunica-se por libras. A garota eu não conheço. A conversa segue sem que participemos dela. Depois de algum tempo o garoto vem até a nossa mesa, cumprimenta oralmente e me pergunta se sei o nome de uma série nova de tevê sobre duas garotas que foram trocadas na maternidade que havia sido comentada em uma de nossas aulas. Ele me faz recordar a situação e informa que a mesma ainda não está na tevê e que os quatro queriam acessar pela internet. Ri e em tom brincalhão diz que como sou jornalista e domino o inglês poderia saber. Eles estão interessados na série porque a mesma aborda os problemas enfrentados pelos surdos em vários lugares e na escola. Rio e penso um pouco, lembro da situação e respondo Switched at birth. Ele agradece e volta à conversa. (Excerto do diário de campo, 31 out. 2012)

Pensando sobre a escola como um dos lugares em que os jovens surdos constroem suas redes de sociabilidade lembro-me da situação vivida e registrada em meu diário de campo que exponho aqui, pois a conversa me motivou a buscar mais informações sobre a série televisiva Switched at birth [Trocadas no nascimento] como forma de compreender como também as produções midiáticas, muitas vezes acessadas pelos vários ambientes da internet e por suas temáticas estão imbricadas na produção das identidades e culturas juvenis. Tal série produzida e veiculada pela rede de tevê norte-americana $A B C$, uma das componentes do Grupo Disney, através do canal a cabo $A B C$ Family e pelo site oficial da rede somente para os Estados Unidos, onde estreou em junho de 2011, registrando cerca de 3.3 milhões de telespectadores ao vivo. Ao longo da primeira temporada originalmente planejada para dez episódios semanais e alargada para trinta, Switched at birth manteve a média de 2.7 milhões de telespectadores ao vivo. 0 último episódio foi exibido em agosto de 2012 
e a estreia da próxima temporada está sendo trabalhada pela equipe de divulgação da rede para início de janeiro do próximo ano (Furquim, 2012).

A razão para abordar tal produção midiática aqui, quando busco caracterizar a escola como um dos elementos dos circuitos produzidos por jovens surdos que circulam em Porto Alegre através de suas redes de sociabilidade, conectividade e espaços de lazer, está relacionada a esta ampliação dos espaços pedagógicos no âmbito da cultura contemporânea que acabam por nos ensinar a ser sujeitos de tal ou qual tipo. Criada por Elizabeth Weiss, Switched at Birth narra a história de duas adolescentes trocadas no hospital quando eram recém-nascidas. Bay Kennish cresceu em uma família rica cercada pela atenção de seus pais, John, ex-jogador de beisebol, e Kathryn, bem como de seu irmão Toby que é músico. Daphne Vasquez cresceu em um bairro hispânico, na companhia de sua mãe, uma cabelereira de bairro solteira, Regina.

No contexto deste artigo, interessa destacar que na trama, Daphne ainda muito pequena contrai meningite ficando surda e sendo educada em uma escola especial para surdos, mas conseguindo se comunicar com as pessoas ouvintes com as quais tenha contato visual para que ela possa fazer leitura labial. As duas famílias se encontram por acaso e ao descobrirem sobre a troca dos bebês, decidem permanecer juntos. Nos trinta episódios já veiculados e disponíveis em vários locais da internet vários tópicos que ainda hoje pautam a comunidade, a cultura (juvenil) e as identidades (juvenis) surdas estão ali abordados, além de a trama desenvolver-se tendo a vida escolar como uma referência importante, razão da repercussão da série junto aos jovens surdos brasileiros, pois como analisa Murray (2008) para compreender as vidas surdas é preciso percebê-las em uma perspectiva transnacional, uma vez que a comunidade surda por não se estabelecer a partir de um determinado território, mas desde uma cultura singular a partir de uma determinada forma de língua gestual visual que se articula com várias culturas, mantém contatos consistentes que vão além das fronteiras nacionais. 
Ao visitar o site oficial da série, um detalhe chama a atenção: a partir dos episódios, o ator Lucas Grabeel, bastante conhecido do público juvenil por sua participação em High School Music, outra produção da Disney para este segmento de público, ensina frases que aparecem nos episódios em ASL, língua de sinais americana. No referido link, o jovem internauta é convidado a "aprender a língua de sinais com Lucas Grabeel”. O link que está disponível desde outubro, período em que as séries norte-americanas estão "em férias", indaga se o jovem fã conhece a série de vídeo aulas que ensinam a língua de sinais e convoca os fãs a conferirem a cada semana, depois de cada novo episódio, as novas frases em ASL, pois este é "um bom sinal" (ABC Family, 2012).

A partir do cenário já desenhado, assinalo a urgência de uma ampliação da compreensão das práticas sociais e relações de poder implicadas no conhecimento, entrelaçadas pela escola. Steinberg e Kincheloe (2001) reforçam esta ligação quando afirmam que as práticas culturais e as relações de poder e conhecimento dizem respeito à Educação, não só porque, com as mídias e tecnologias digitais de conectividade, os espaços pedagógicos na vida cotidiana são ampliados, como também 'atravessam' os lugares tradicionais da pedagogia - especialmente a escola - a partir dos conhecimentos e instituições que são trazidos pelos jovens alunos, neste caso surdos, e produzem efeitos sobre as suas redes de sociabilidade.

\section{Próxima parada, o shopping: a gente se encontra na praça de alimentação, depois...}

Tarde de sábado, final de inverno, mas ainda faz frio. Estou na praça de alimentação do shopping Bourbon Country, um dos vários que existem nesta área da cidade. Espero o horário de almoço quando vários jovens estudantes surdos de uma escola de surdos privada localizada na zona leste da cidade se reunem. Esta não é a primeira vez que os encontro aqui. Nos nas sextas e sábados, este parece ser o point e o roteiro pare- 
ce previamente produzido: primeiro todos se reunem para o lanche do McDonalds e aquele imenso prato de batatas fritas. Depois de umas três horas de muita conversa e entra-e-sai de integrantes do grupo, é hora da sobremesa, invariavelmente sorvete de maquina do McDonalds. Sabores: chocolate e chocolate e creme. Garotos e garotas parecem estar com o mesmo uniforme: camiseta da escola ou com alusão a alguma campanha específica das lutas surdas, jeans na forma de calças, bermudas, saias...0 visual também é composto por bonés, cabelos coloridos, piercings, colares e lenços. Alguns usam jaquetas da escola, outros casacos impermeáveis. Nos pés, tênis e botas, afinal, ainda faz frio. E nas mãos, os celulares, de todas as marcas e modelos, mas sem dúvida com acesso à internet!!(Excerto diário de campo, 11 ago.2012)

Os shopping centers têm sido apontados pelos estudos de marketing e comportamento do consumidor como lugares preferências dos jovens que buscam lazer coletivo com segurança nas grandes cidades. Além de oferecerem um ambiente, como constatou Vitelli (2008) repleto de estimulos sonoros, visuais e olfativos, em outras palavras, música ambiental, vitrines, marcas, decoração sazonal, lojas com diversos perfumes, livrarias, cinemas, pessoas que olham e são olhadas. Assim, neste momento inicial da pesquisa, como destaco através do excerto do diário de campo transcrito acima, olho para um dos shopping centers da zona leste de Porto Alegre em que constatei intensa frequencia de jovens surdos, principalmente estudantes de uma tradicional escola de surdos privada, confessional, ainda durante a pesquisa de doutorado anteriormente citada: o Bourbon Country, localizado próximo a dois bairros de classe média alta - Três Figueiras e Jadim Europa -, mas também próximos de outros bairros de classe média e média baixa como a Vila Jardim, Chacara das Pedras, Cristo Redentor entre outros.

Como equipamentos urbanos de consumo, entretenimento e lazer, os shoppings centers cada vez mais se preparam para receber seus jovens visitantes/habitantes/consumidores, pois como explicitam Oliveira, Tschiedel e Pereira (2011), eles represen- 
tam uma parcela significativa da população brasileira e, desta forma, mesmo comumente sem renda própria e dependendo dos pais para custearem o que consomem, são frequentemente visados e 'assediados' por empresas e marcas dos mais variados segmentos que os vêem como potenciais consumidores. Ainda conforme as autoras, "os seus hábitos, crenças e valores devem ser analisados, pois se constituem em importantes indicativos daquelas que serão suas preferências de compra" (Oliveira, Tschiedel e Pereira, 2011, p. 113).

Entretanto, esclareço na perspectiva teórica adotada neste artigo, o consumo não se reduz às estratégias comerciais das empresas e atos de compra dos consumidores, mas está localizado no âmbito das práticas culturais, como uma dimensão da vida social fundamental nas sociedades urbanas contemporâneas, pois os bens carregam significados e atuam como sistemas de comunicação, e os indivíduos - os jovens surdos que circulam em Porto Alegre - os utilizam para produzirem significados sobre si mesmos, sobre os outros e sobre o mundo que habitam, engendrando assim um universo compreensível (Silva, 2007).

Assim, na perspectiva proposta por Steinberg e Kincheloe (2001) anteriormente, penso o consumo, como prática cultural, como pedagógico, pois é possível constatar no âmbito da escola e fora dela as formas como garotos e garotas 'capitalizam' suas vontades de pertencimento através não só da produção e circulação de artefatos que os identificam com determinadas ideias, modalidade esportiva ou lugar de lazer, mas replicando os estilos de artistas, atletas, personagens preferidos tomados como modelos a serem seguidos; transformando tais elementos em uma espécie de marca em nível de mercado e em marcador identitário relativamente a uma determinada juventude que se distingue visualmente das demais que circulam nos ambientes urbanos.

Refletir sobre este processo vivido pelos jovens surdos possibilita visualizar a juventude como uma condição, um sintoma cultural con- 
temporâneo, como uma construção histórica que se articula sobre recursos materiais e simbólicos cuja distribuição social é assimétrica, conforme Margulis e Urresti (2000) e García Canclini (2005). Os autores enfatizam que "se é jovem de diferentes maneiras em função da diferenciação social, de parâmetros como o dinheiro, o trabalho, a educação, o bairro, o tempo livre. A condição de juventude não se oferece de igual maneira para todos os integrantes da categoria estatística jovem" (Margulis e Urresti, 2000, p. 133).

Considerando tais aspectos, Margulis e Urresti (2000) enfatizam ser necessário considerar a significação atribuída em determinado contexto ao que é consumido no sentido de identificar, distinguir, conferir prestígio, localizar em determinada categoria social a quem consome. Os autores ressaltam a efemeridade da moda e a fragilidade das identidades engendradas a partir dela. Os jovens que orientam suas práticas de consumo pela moda buscando pertencimento, reconhecimento, legitimidade e, nesta direção, adaptam suas formas de vestir, linguagem corporal, fala, preferências musicais e aparência ao grupo a que desejam pertencer, estão sujeitos à incerteza que supõe construir a identidade pessoal sobre uma exterioridade em mudança e aceleração permanente: a moda opera no limite da legitimidade e da exclusão, requer bens e destrezas culturais.

A partir desta lógica cultural, arrisco afirmar que tecnologia e conectividade, junto aos jovens surdos que circulam pelas escolas e shoppings centers observados em Porto Alegre, e também por outros lugares, estão na moda e múltiplas são as táticas e destrezas culturais exigidas para nela permanecer e pertencer/ distinguir-se nos vários grupos juvenis que compõem a comunidade surda. Silva $(2007,2009)$ estudou a utilização de telefones celulares e o uso do bluetooth - uma tecnologia de transmissão de dados ou voz, de fraco alcance, flexível, que permite interligar aparelhos sem utilização de cabos, à curta distância a partir de uma espécie de circuito de rádio - para reduzir o custo do uso do celular por garotos de uma comunidade de Florianópo- 
lis. Segundo a autora, considerando que a posse de celulares entre garotos das camadas populares é bem superior ao acesso à internet no ambiente doméstico, o bluetooth tem cumprido um importante papel no compartilhamento de arquivos especialmente musicais. Silva (2009, p. 1) argumenta que "desta forma, um membro de um grupo de amigos que tem acesso à internet pode passar músicas e outros conteúdos para celulares de amigos, que por sua vez repassam esse conteúdo via bluetooth para tantos outros, estabelecendo uma identidade comum que é tornada pública nos espaços coletivos".

Situações semelhantes foram observadas junto aos jovens surdos frequentadores do Bourbon Country e remetem às práticas observadas no trem interurbano, nos ônibus da cidade e em eventos esportivos, nas quais se incluem os jovens ouvintes. Possuir um artefato sonoro portátil, dominar tal tecnologia, ter a destreza mental para utilizá-la e demonstrar que sabe fazê-lo em público, é uma forma destes garotos se distinguirem uns dos outros e através de suas práticas e terem determinadas posições reconhecidas pelos grupos que integram. Considerando este aspecto, inferimos que no caso dos jovens surdos o acesso às redes sociais e o manejo da produção e distribuição de vídeos em ambientes como You Tube - ambiente virtual no qual são postados vídeos de livre acesso aos internautas - são centrais às práticas culturais relativas à conectividade e sua relação com a produção de identidades juvenis surdas, principalmente urbanas.

De forma específica, relativamente às culturas juvenis surdas, a adesão às várias campanhas de reconhecimento de direitos da comunidade surda - Escola Bilíngue para Surdos, Legenda para quem não ouve, mas se emociona, Respeito às Línguas de Sinais e a cultura surda, por exemplo -, expressas em camisetas que manifestam tal adesão e marcam seus corpos, bem como a afiliação à determinada comunidade escolar demonstrada a partir do uso dos uniformes em diversos espaços urbanos, entre os quais os ambientes do shopping center, constituem marcadores culturais 
identitários que diferenciam cada jovem surdo dos demais e, ao mesmo tempo, os une como iguais.

Sobre a relação dos modos de vestir com a frequência aos shopping centers como lugares de encontro, Vitelli (2008) comenta que ambos estão ligados a uma determinada estética (sentimento comum) cotidiana partilhada que funciona como elemento de coesão grupal. Neste sentido, e a cultura surda tem a expressão corporal como um marcador cultural importante, assim como o olhar que constitui ao surdo e ao outro, concordo com o autor quando afirma que "o foco recai, portanto, sobre o vestuário, o 'figurino', todas as formas de cobrir ou mostrar o corpo e que servem de estandarte, muitas vezes, de ideias, de elos de pertença e mesmo de maneiras de viver essa juventude" (Vitelli, 2008, p. 28).

Outro aspecto a destacar nestas primeiras incursões de (re) conhecimento do campo para a efetivação desta pesquisa diz respeito a relação que os jovens surdos parecem manter com, principalmente, seus telefones móveis e que fica bastante evidenciado na circulação dos mesmos nos vários espaços do Bourbon Country. Tal qual ressalta Silva (2007) estes dispositivos portáteis parecem ser 'acoplados' como parte dos corpos destes jovens, prolongamentos das possibilidades expressivas e comunicacionais. Uma vez que saem de bolsas, mochilas e bolsos, não retornam. É comum vê-los com os telefones móveis nas mãos, seguros, e constantemente checados. Esta prática pode ser mais intensamente notada nas salas de cinema, pois a cada checagem ou 'conversa' mantida através de mensagens instantâneas e tela é iluminada e se destaca no ambiente escuro.

Entretanto, além do telefone móvel, mais recentemente, outros tipos de dispositivos portáteis tais como ipads, tablets e microcomputadores têm 'frequentado' os espaços do shopping center observado. Os jovens surdos acessam intensamente múltiplos ambientes na internet, tais como o culturasurda.com onde podem ser encontradas várias produções culturais, lista de inter- 
nautas, links para associações de surdos com diferentes interesses e de diversos países, escolas e instituições, organizações e blogs, além de um link para enfoques diversos sob o título Geral. Ali estão disponíveis vários arquivos para serem transferidos e que acabam por constituir um 'acervo próprio' para ser consumido individualmente de forma cotidiana ou mesmo intercambiado através do bluethooth ou de outras tecnologias, conformando uma espécie de 'acervo coletivo' comum.

Como a equipe do próprio site culturasurda.net (2012) anuncia em sua página inicial, ele se constitui como

um espaço para a partilha e promoção de produções
culturais relacionadas a comunidades surdas de dife-
rentes países do mundo. Artes plásticas, literatura, teatro,
filmes, projetos, músicas em línguas gestuais: as culturas
surdas em exibição. Vídeos, links, textos, entre aspas e si-
nais. Produções de, para e sobre o público Surdo, parti-
lhadas neste espaço virtual em língua portuguesa. (Cultura
Surda, 2012)[destaque dos autores]

A equipe adverte o jovem internauta surdo, e também aos ouvintes, que aquele é "um site simples, com atualizações constantes e navegação descomplicada para tornar mais fácil e rápido o acesso às produções culturais aqui divulgadas", e que para acessar a totalidade do conteúdo do culturasurda.net, o mesmo está "organizado por temas, clique em LISTA na barra de menu acima" (Cultura Surda, 2012).

$\mathrm{Na}$ página inicial do culturasurda.net o internauta encontra ainda 'botões' para compartilhar os conteúdos e o próprio site através do Twitter e do Facebook, além de um espaço para registrar seus comentários. 0 site também expõe neste ambiente as logomarcas de várias campanhas que vêm sendo desenvolvidas pelas organizações representativas da comunidade surda. Tais logomarcas já citadas anteriormente são as mesmas que circulam como estamparia em camisetas usadas pelos jovens surdos 
'sempre conectados' e em movimento, tanto nas escolas como 'parte do uniforme', como nos espaços de lazer por onde circulam e no transporte público que utilizam.

Ainda no culturasurda.net é possível ler um chamamento à defesa dos direitos do povo surdo em todas as suas diferenças e para que surdos e ouvintes participem destas lutas. Sua equipe convida o visitante a participar, opinar, criticar, discutir e divulgar o espaço virtual. Sobre o site, a jovem internauta surda, Camila Lopes do Nascimento, comentou através do Facebook, em junho deste ano: "Excelente blog! Foi uma grande ajuda para meu TCC [Trabalho de Conclusão de Curso], e também serviu para ampliar meu conhecimento. Me faz sentir mais orgulho de ser surda! Muito obrigada pois não encontro mais as palavras para expressar a minha gratidão." (Cultura Surda, 2012).

Ainda olhando as relações dos jovens surdos com a tecnologia digital como lugar de interação e sociabilidade, tenho observado o intenso uso destes do You Tube como uma possibilidade de produção e divulgação de conteúdos políticos, educacionais e de entretenimento, através da qual os jovens sujeitos surdos têm se representado aos outros e produzido a si mesmos. Representar como argumenta Hall (1997b) não é um simples reflexo de uma realidade externa suposta, nem uma imposição de sentidos do espectador/leitor ao objeto, mas uma produção de significados através de práticas e processos de simbolização. Concordando com Serrano (2002, p. 16) quando analisa as representações produzidas pelas narrativas de jovens e pelos discursos sobre 'a juventude', representar a alguém ou a si mesmo é acima de tudo criar ficções, mais ou menos legítimas e acreditáveis; é uma prática cultural que diz sobre quem representa o outro e a si e as lógicas com as quais opera.

Reconheço aqui que tais práticas culturais juvenis, para além de estarem relacionadas a pedagogias culturais que implicam na produção, circulação e consumo da cultura surda, como tem sido 
investigado por Pinheiro (2012), mais amplamente têm implicações nas relações familiares, aparentemente mais próximas do nosso cotidiano, bem como nas relações entre os diversos atores da indústria do entretenimento e das tecnologias de conectividade e seus potenciais públicos juvenis.

Sobre as implicações nas relações familiares, Nicolaci-Da-Costa (2007), focando o uso dos celulares, comenta que, muitas vezes, eles são dados aos jovens por seus pais como forma de mantê-los sob algum controle em razão da complexidade dos trânsitos da vida urbana contemporânea. Se o celular inicialmente apazigua pais e mães que pensam ter seus filhos ao alcance do teclado, ele se transforma em um presente dos céus nas mãos destes mesmos jovens que fazem usos variados desta tecnologia. Tais celulares, às vezes, destaca a autora, acabam se convertendo em elementos de insegurança, ora porque os jovens os codificam de diferentes formas e sabem quando são seus pais que buscam contato, não atendendo; ora porque são objetos de desejo de assaltantes.

\section{Sempre (des)conectados e em movimento: jovens surdos e novas sensibilidades}

As práticas culturais de jovens surdos, assim, conforme o cenário tecido aqui, são tomadas como marcadores culturais identitários que possibilitam a definição ou não do pertencimento dos jovens a determinados grupos e estão profundamente atravessadas pelo imperativo da conectividade e seu par a desconexão. Estar ligado através dos telefones celulares e da internet implica estar desligado de outras possibilidades tecnológicas e de comunicação interpessoal com o outro.

Martín-Barbero (2001) argumenta que esta lógica de fruição está relacionada às novas sensibilidades, ou seja, a uma experiência cultural constituída por novos modos de perceber e de sentir, de escutar e de ver que caracterizam os jovens contempo- 
râneos e se expressam na forma como habitam suas cidades e se relacionam com a tecnologia. Para este autor a partir de um processo de desenraizamento que se transforma em deslocalização, eles habitam as cidades de maneira nômade: deslocam periodicamente seus lugares de encontro, atravessam a cidade em uma explosão que tem muitas relações com a travessia televisiva que permite o zapping - programação feita de restos e fragmentos de programas, telenovelas, informativos, esportes e espetáculos musicais. Contudo, estes jovens inscrevem-se no mundo a partir de uma profunda empatia com as tecnologias, pois constituem uma geração de sujeitos culturais que não possuem ou possuem uma fraca identificação com figuras, estilos e práticas de antigas traições que tem definido 'a cultura'[grifo do autor].

Ainda segundo Martín-Barbero, é a partir de conexões/desconexões (jogos de interface) com artefatos, de uma enorme facilidade para o domínio dos idiomas das tecnologias que implicam uma enorme capacidade de busca e absorção de informações de variados meios, complexas redes informáticas e tecnologias audiovisuais que os jovens conformam seus 'mundos imaginados'. Tais mundos presentes em relatos, imagens, e sonoridades, encontram seu ritmo e seu idioma numa cumplicidade entre uma oralidade como experiência cultural primária que perdura e uma oralidade secundária que tece e organiza as gramáticas tecnoperceptivas da visualidade eletrônica, denominada pelo autor de 'cumplicidade expressiva'.

Diferentes visualidades estão implicadas em um modo contemporâneo de ser jovem, assinala Martín-Barbero (2002, 2004). Elas não estão isoladas, mas integradas às novas formas de sensibilidade engendradas pelas múltiplas telas a que estes jovens estão submetidos, pelos fluxos de informação, pelos trânsitos cotidianos e pela mediação tecnológica. Eles em suas falas conjugam tecnologia com múltiplos elementos. Sentem necessidade de ver e serem vistos, porém o desejo se une a uma determinada estética, a um determinado estilo e um modo de viver que vai 
além da moda, do consumo. No caso dos jovens surdos, conforme descrito por Croneberg (1976), historicamente um desejo de estar junto e de pertencer que se mistura a um tipo de nostalgia de um ser surdo imaginado.

Martín-Barbero (2004) destaca que, no contexto da sociedade midiatizada contemporânea, há uma convivência da cultura massiva com estas 'novas tecnicidades' caracterizadas pela mobilidade, portabilidade, conectividade e simultaneidade. Neste sentido, principalmente junto às populações de menor poder aquisitivo, as lan houses têm desempenhado um papel social importante, relativamente ao acesso à internet e aos produtos desenvolvidos através dela. Sua presença é cada vez maior, principalmente nos pequenos e médios municípios brasileiros.

Neste sentido, não existe uma juventude única, mas 'juventudes', argumentam Nilan e Feixa (2006), quando indagam sobre a existência ou não de uma juventude global e constatam que, ainda que os jovens possam estar expostos à interpelação de uma produção midiática quase comum, a forma como produzem suas identidades está atravessada por traços de classe social, gênero, raça/etnia, marcas do lugar onde vivem, dos grupos etários a que pertencem e da diversidade cultural a que estão expostos que, juntamente com diferenças como a surdez, constituem as singularidades do juvenil abordadas por Serrano (2002). Feixa (2006) reitera, assim como Murray (2008) o faz especificamente sobre a surdez, que em tempos de globalização, o estudo das culturas juvenis seria mais bem desenvolvido de forma transnacional, pois as possibilidades de conexão e informação têm se multiplicado e um mesmo fenômeno adquire nuances locais, ainda que tenda a se manifestar em vários países.

Neste contexto, argumenta Appadurai (2005), múltiplas imagens em circulação, através dos mais variados artefatos e textos culturais participam da 'fabricação' de 'mundos possíveis' a partir da constituição de imaginários globais e locais articulados 
em panoramas subjetivos presentes na imaginação de sujeitos de diferentes partes do planeta, expandindo as possibilidades de produção de comunidades de sentido e disseminando práticas e marcas identitárias que constituem as culturas em que se inscrevem os jovens (surdos e ouvintes) urbanos contemporâneos.

Vale aqui lembrar García Canclini (2005), quando nos provoca a refletir sobre as formas como a globalização pensada de forma circular tem integrado as práticas cotidianas das juventudes. 0 autor observa que, mesmo com a inovação das tecnologias de comunicação, das formas de medir o consumo cultural e do desenho de estratégias e programas midiáticos na busca da ampliação do conhecimento massivo e do consenso social, há nas práticas cotidianas dos jovens contemporâneos algo que escapa aos conceitos e ideias amplamente difundidos. Através destas práticas, os jovens parecem negociar com elementos que, ao mesmo tempo em que fortalecem uma uniformização do mundo num mercado planetário, multiplicam diferenças, geram singularidades e tensões.

Considerando a argumentação de Appadurai (2005) sobre as imagens oferecidas pela cultura contemporânea, principalmente pelas produções midiáticas e pelas produções 'artísticas' que interpelam os jovens urbanos contemporâneos, podemos afirmar com Hernandez (2007, p.24) que habitamos um mundo visualmente complexo e estamos vivendo um novo regime de visualidade, profundamente articulado com a técnica, com as mídias, no qual a tecnicidade é uma das possibilidades mais intensas de mediação cultural (Martín-Barbero, 2004). No mesmo sentido, observa García Canclini (2003), que as identidades podem mostrar-se na cultura visual através dos diversos sistemas de imagens e desenhos presentes na organização simbólica de cada sociedade que podem ou não se cruzar e interpenetrar.

No mesmo sentido, concordo com Hernandez (2007) quando afirma que a cultura visual - constituída pelos artefatos culturais produzidos em grande escala industrial e comercial e de fácil 
aceitação pelos consumidores, que incluem desde as imagens mais corriqueiras, presentes em revistas, jornais, filmes, vídeos, programas televisivos, campanhas publicitárias, logomarcas, outdoors, videogames, sites, até as imagens da arte - contribui para que os indivíduos fixem representações sobre eles mesmos, sobre os outros, sobre o mundo e sobre seus modos de pensá-los.

Assim, é possível pensar nos jovens contemporâneos, e muito especialmente nos jovens surdos em razão de conhecerem/construirem o mundo peculiarmente pelo olhar, como catadores de imagens e histórias a partir de Hernandez (2007) quando propõe que metaforicamente nos consideremos catadores de restos, tomando a ideia de 'catar' da tradição agrícola ligada à atividade daqueles que recolhem os restos, os reciclam e deles se nutrirem. Segundo o autor, esta metáfora possibilita que rompamos com o discurso dualista que dá origem a pares deterministas, entre os quais emissor/receptor, arte/popular, autor/leitor, produtor/consumidor, ensinar/aprender que deixam poucas possibilidades à capacidade de ação, de resistência e de reinvenção dos sujeitos, reduzindo os problemas a esquemas simplificados, minimizando sua complexidade.

Tomando a cultura visual como uma forma de discurso que coloca, no debate político e da educação, a centralidade da 'subjetividade', pensando a prática de 'catar' como a possibilidade criativa de ruptura, de reinvenção e transformação, Hernandez (2007) se aproxima de Willis (1990), ao estudar as culturas juvenis como culturas cotidianas, ordinárias, caracterizadas como 'trabalho criativo'. Este autor afirma que o universo da cultura da mídia eletrônica - e eu incluiria digital - se constitui em uma importante fonte simbólica, poderosamente estimulante quando abordamos o trabalho criativo que a juventude produz a partir de seus fragmentos. 0 jovem aprenderia, de forma privilegiada, a reinterpretar códigos, reformatar produtos e mensagens, a partir da produção de um repertório atravessado por múltiplas referências. Segundo Hernandez (2007, p.18), este conjunto de 
possibilidades transformadoras liga-se ao fato de que os catadores atuais, além de "recolherem amostras e fragmentos da cultura visual de todos os lugares e contextos para colecioná-los e lê-los", produzem "narrativas paralelas, complementares e alternativas, para transformar os fragmentos em novos relatos mediante estratégias de apropriação", distanciados de dualismos, subordinações e limites. Inscritos no sistema capitalista, os catadores, ao se apropriarem de e reaproveitarem os restos "como excedente cotidiano necessário para que o consumo se mantenha em tensão constante" (p. 19), realizam um 'ato de subversão' rompendo com o papel a eles atribuído no interior da cadeia de consumo, inventando novas subjetividades.

Neste sentido, as práticas juvenis surdas e conectividade das quais estive falando até aqui, são mostrada, muitas vezes, em produções midiáticas endereçadas aos jovens surdos e às quais eles têm acesso e referem nas redes sociais e em suas conversas no âmbito da escola. Filmes produzidos para cinema - e que são assistidos também em outras telas menores como tevês, computadores e tablets, individual ou coletivamente, em espaços privados ou públicos -, telenovelas e peças de comunicação publicitária - legendadas ou traduzidas para a língua brasileira de sinais, ainda que em menor volume, colocam em circulação imagens que mostram/sugerem tais práticas.

A produção chinesa taiwanesa, Hear me [Escuta-me] (2009) pode ser tomada como um exemplo. Caracterizado como um romance juvenil, o filme disponível originalmente em taiwanês, inglês e em língua taiwanesa de sinais, narra o envolvimento de dois jovens taiwaneses: Yang Yang e Tian Kuo. Ela uma estudante que trabalha nas ruas como artista de rua para sustentar a irmã Xiao Peng, uma nadadora surda que se prepara para os Jogos Olímpicos Surdos e sonha com a medalha de ouro, ambas filhas de um missionário cristão que está fora do país. Ele um estudante, entregador de refeições preparadas pelo restaurante dos pais. Os conflitos que movem o enredo giram em torno da cultura sur- 
da e de como os pais do rapaz que é ouvinte aceitarão, ou não a namorada surda. Contudo, este é um mal-entendido, apesar de se comunicarem através da língua taiwanesa de sinais, os dois não são surdos, mas pensam que um e outro o são. A trama é construída tendo como base os conflitos existentes relativamente aos preconceitos com a surdez e a 'descrição' de um modo de viver onde a surdez é a norma e não a audição, sendo assinalada a diferença que constitui o surdo e não a sua falta de audição, segundo argumentam Padden e Humphries (1988).

Ainda sobre a produção cinematográfica Hear Me, interessa no contexto desde artigo destacar a relação dos jovens com as tecnologias móveis e de conectividade. Várias são as cenas de caráter mais descritivo em que o garoto e a garota são caracterizados como 'jovens, urbanos, contemporâneos' a partir do uso de telefones celulares e mensagens instantâneas, da navegação em sites de relacionamentos, onde a partir de uma micro câmera conversam em língua taiwanesa de sinais e da escrita em taiwanês. Em cenas ambientadas nas ruas, a presença da tecnologia através das fotografias capturadas a partir dos telefones móveis, assim como de uma indumentária composta por camisetas, calças jeans, tênis, mochilas e bonés e a presença intensa de elementos de campanhas midiáticas de marcas reconhecidas como juvenis, são expostas reiteradamente.

Desta forma, a partir de Giddens (2002) penso que, relativamente às identidades e culturas juvenis surdas, eleger um estilo de vida aparece como parte de uma espécie de projeto de autoconstituição identitária sempre em construção a partir da escolha de 'modelos' que a cultura contemporânea em articulação com uma memória da comunidade surda oferece em um processo de reflexividade 'interminável', de construir-se a si mesmo a partir de escolhas que se multiplicam. Os jovens surdos constroem suas identidades a partir de elementos de várias origens, o que no âmbito das culturas juvenis é pensado por Feixa (2006) como estilos de vida, pois para este autor, as culturas juvenis se referem em sentido amplo à 
"maneira como as experiências sociais [e culturais] dos jovens são expressas coletivamente mediante estilos distintivos, localizados fundamentalmente no tempo livre, ou em espaços intersticiais da vida institucional" (Feixa, 2006, p.84)

Fixo esta imagem como possibilidade de compreensão futura das dinâmicas constatadas junto aos jovens surdos que tenho observado e ainda vou observar, pois suas práticas fornecem indícios deste 'catar' e nos deixam perceber através das formas como se produzem integrantes desta ou daquela cultura juvenil urbana, articulando elementos de diferentes temporalidades e produzindo o que Martín-Barbero (2001) caracteriza como destempos, ou a convivência do múltiplo, dos vários tempos simultaneamente, na forma do palimpsesto, como característica de um novo regime de sensibilidades que articula as diferentes possibilidades oferecidas pela tecnologia.

\section{Ref erências Bibliográficas}

APPADURAI, Arjun Modernity at Large: cultural dimensions of globalization. 7ed. Minneapolis: University of Minnesota Press, 2005.

BAUMAN, H-Dirksen L. (ed.). Open Your Eyes: Deaf Studies Talking. Minneapolis: University of Minnesota Press. 2008.

CARRANO, Paulo. Identidades culturais juvenis e escolas: arenas de conflito e possibilidades. In: MOREIRA, Antônio Flávio; CANDAU, Vera Maria (orgs). Multiculturalismo: diferenças culturais e práticas pedagógicas. 2 ed. Petrópolis, RJ: Vozes, 2008. p. 182-211.

CHAMBERS, Iain. Migrancy, culture, identity. Oxon: New York: Routledge, 2005. CRONEBERG, Carl G. The Linguistic Community, Appendix C. In: STOKOE, William C,Jr; CASTERLINE, Dorothy C.; CRONEBERG, Carl G. A Dictionary of American Sign Language on Linguistic Principles. Silver Springs, Md: Linstok Press, 1976. New Edition. p. 297-311.

DAYRELL, Juarez. A escola "faz" as juventudes? Reflexões em torno da socialização juvenil. Educação e Sociedade, Campinas, vol.28, n.100 - Especial, p. 1105-1128, out.2007. 
DE CERTEAU, Michel. A Invenção do Cotidiano. Petrópolis, RJ: Vozes, 1997.

FEIXA, Carles. A construção histórica da juventude. In: CACCIA-BAVA, Augusto; FEIXA, Carles; GONZÁLES, Yanko.(org) Jovens na América Latina. São Paulo: Escrituras, 2004. p.257- 327.

FEIXA PAMPOLS, Carles. De jóvenes, bandas y tribos. 2 ed. rev. e ampl. Barcelona: Ariel, 2006.

FURQUIM, Fernanda. Switched at birth terá novos episódios para sua 1aㅡ temporada. Disponível em:< http://veja.abril.com.br/blog/temporadas/tag/switched-at-birth/>. Acessado em 2 nov. 2012.

GARAY, Adrián de. El Rock como Conformador de Identidades Juveniles. Nómadas. Santafé de Bogotá, n.4. p. 10-15, mar-ago. 1996.

GARCÍA CANCLINI, Néstor. A Globalização Imaginada. Trad. Sérgio Molina. São Paulo: Iluminuras, 2003.

GARCÍA CANCLINI , Néstor. Diferentes, Desiguais e Desconectados - mapas da interculturalidade. 2 ed. Rio de Janeiro: Editora UFRJ, 2007.

GEERTZ, Clifford; CLIFFORD, James, (org.). El Surgimiento de la Antropologia Posmoderna. Comp. e Trad. Carlos Reynoso. Barcelona: Gedisa, 1992.

GEERTZ, Clifford. Estar lá, escrever aqui. Tradução de Mario Salviano Silva. Diálogo, São Paulo, v. 22, n. 3, p. 58-63, 1989.

GOTTSCHALK, Simon. Postmodern Sensibilites and Ethnographic Possibilities. In: BANCKS, Anna; BANCKS, Stephen P. (eds.). Fiction and Social Research: by ice or fire. Walnut Creek/ London/ New Delhi: Altamira Press, 1998. p. 206227.

GREEN, Bill \& BIGUM, Chris. Alienígenas na Sala de Aula. In; SILVA, Tomaz Tadeu da (org.). Alienígenas na Sala de Aula. Uma Introdução aos Estudos Culturais em Educação. Trad. Tomaz Tadeu da Silva. 4ed. Petrópolis: Vozes, 2002. p. 208-243.

HALL, Stuart. Quem Precisa de Identidade? In: SILVA, Tomaz Tadeu da (Org.). Identidade e Diferença: a perspectiva dos estudos culturais. Petrópolis, RJ: Vozes, 2005. p.103-133.

HALL, Stuart. Da Diáspora: identidades e mediações culturais. Belo Horizonte: UFMG, 2003.

HALL, Stuart. Identidades Culturais na Pós-Modernidade. Trad. Tomaz. T. da Silva e Guacira Louro. 2 ed. Rio de Janeiro: DP\&A, 1999. 
HALL, Stuart. A Centralidade da Cultura: notas sobre as revoluções do nosso tempo. Educação \& Realidade. Porto Alegre, v.22, n.2, p. 15-46, jul./dez. 1997.

HOLCOMB, Roy; HOLCOMB, Samuel; HOLCOMB, Thomas. Deaf Culture - Our Way: Anecdotes from the Deaf Community. 3ed. San Diego, California: Dawn Sign Press. 1994.

KANNAPELL, Barbara. Deaf Identity: an American Perspective. In: ERTING, Carol J. et. al.(ed.) The deaf way: perspectives from the International Conference on Deaf Culture. Washington D.C.: Gallaudet University Press, 1994. p. 44-48

KARNOPP, Lodenir. B.; KLEIN, Madalena.; LUNARDI-LAZZARIN, Márcia.(org.) Cultura Surda na Contemporaneidade: negociações, intercorrências e provocações. Canoas, RS: Editora da ULBRA, 2011.

LADD, Paddy. Understanding Deaf Culture: In Search of Deafhood. Bristol, UK: Multilingual Matters, 2003.

LANE, Harlan, HOFFMEISTER, Robert, BAHAN, Ben. A journey into the deaf word. San Diego, California: DawnSignPress, 1996.

LOPES, Maura C.; THOMA, Adriana da S. (Orgs.). A invenção da surdez: cultura, alteridade, identidade e diferença no campo da educação. Santa Cruz do Sul, RS: EDUNISC, 2004.

LOPES, Maura C.; VEIGA-NETO, Alfredo. Marcadores culturais surdos: quando eles se constituem no espaço escolar. Perspectiva, Florianópolis, v.24, n. Especial, p. 81-100, jul./dez. 2006.

MAGNANI, José Guilherme Cantor. A antropologia urbana e os desafios da metrópole. Tempo Social, Revista de Sociologia da USP [online], vol.15, n.1, p. 81-95, 2003. Disponível em: <http://www.scielo.br/pdf/ts/v15n1/v15n1a05. pdf $>$. Acesso em 10 out 2011.

MAGNANI, José Guilherme Cantor. Os circuitos dos jovens. Tempo Social, Revista de Sociologia da USP, São Paulo, v. 17, n.2, p.173-205, nov. 2005.

MAGNANI, José Guilherme Cantor. "Vai Ter Música?": para uma antropologia das festas juninas de surdos na cidade de São Paulo. Revista do Núcleo de Antropologia Urbana da USP. 2007. Disponível em: < http://scholar.google.com. $\mathrm{br} / \mathrm{scholar}$ ?q=Vai+ter $+\mathrm{m} \% \mathrm{C} 3 \%$ BAsica $\% 3 \mathrm{~F} \% 3 \mathrm{~A}+$ Por + uma + antropologia + das + festas + juninas + de + surdos + da + cidade $+\mathrm{de}+\mathrm{S} \% \mathrm{C} 3 \% \mathrm{~A} 3 \mathrm{o}+$ Paulo \&hl $=\mathrm{pt}-$ BR\&btnG=Pesquisar\&lr=>. Acesso em 10 out. 2011.

MAGNANI, José Guilherme Cantor; SILVA, César Augusto de Assis; Teixeira, Jaqueline Moraes. As festas juninas no calendário de lazer de jovens surdos na cidade de São Paulo. 2008. Disponível em: < http://www.fflch.usp.br/ceru/ anais/anais2008_1_ceru04.pdf>. Acesso em 10 out. 2011. 
MARGULIS, Mário; URRESTI, Marcelo. Moda y Juventud. In: MARGULIS, Mário (ed.). La juventud es más que una palabra. 2 ed. Buenos Aires: Biblos, 2000. p. 133-145.

MARTÍN-BARBERO, Jesús. Al sur de La modernidad: comunicación, globalización y multiculturalidad. Pittisburgh: Universidad de Pittisburgh, 2001.

MARTÍN-BARBERO, Jesús. Jóvenes: comunicación e identidad. Pensar Iberoamérica. Revista de Cultura, n.0, fev. 2002. Disponível em: <http://oei.es/pensariberoamerica/ric00a03.htm>. Acessado em 22 de mar. 2009.

MARTÍN-BARBERO, Jesús. Ofício de cartógrafo: travessias latino-americanas da comunicação na cultura. São Paulo: Loyola, 2004.

MARTÍN-BARBERO, Jesús. Pistas para Entre-ver Meios e Mediações. In: Dos Meios às Mediações: comunicação, cultura e hegemonia. Rio de Janeiro: UFRJ, 2003. p. 11-25.

MURRAY, Joseph J. Coequality and Transnational Studies: understanting deaf lives. In: BAUMAN, Dirksen L.. (ed.) Open Your Eyes: Deaf Studies Talking. Minneapolis: University of Minnesota Press. 2008. p. 100-122.

NICOLACI-DA-COSTA, Ana Maria. Celulares: um "presente do céu" para mães de jovens. Psicologia Social, vol.19, no.3, p.108-116, set./dez. 2007. Disponível em: < http://www.scielo.br/pdf/psoc/v19n3/a15v19n3.pdf>. Acesso em 10 set. 2010.

NILAN, Pam; FEIXA, Carles. Introduction: youth hybridity and plural worlds. In: _- (eds). Global Youth? Hybrid identities, plural worlds. London; New York: Routledge, 2006. p. 1-13.

OLIVEIRA, Julienne G. de; TSCHIEDEL, Laura; PEREIRA, Nayana. Os jovens e o shopping center. In: PINTO. Michele L.; PACHECO, Janie K. (orgs.). Juventude, Consumo e Educação3: uma perspectiva plural. Porto Alegre, ESPM, 2011. p. 113-130.

PADDEN, Carol, HUMPHRIES, Tom. Deaf in America: voices from a culture. Cambridge: Harvard University Press, 1998.

PERLIN, Gladis T. 0 lugar da cultura surda. In: LOPES, Maura C.; THOMA, Adriana da S. (Orgs.). A invenção da surdez: cultura, alteridade, identidade e diferença no campo da educação. Santa Cruz do Sul, RS: EDUNISC, 2004. P. 73-82.

PERLIN, Gladis T. Identidades Surdas. In: SKLIAR, Carlos. (org.) Surdez. Um olhar sobre as diferenças. 6ed. Porto Alegre: Mediação, 2012. p. 51-73.

PINHEIRO, Daiane. You Tube como pedagogia cultural: espaço de produção, circulação e consumo da cultura surda. 2012. Dissertação (Mestrado em Educação). Programa de Pós-Graduação em Educação da Universidade Federal de Santa Maria. Santa Maria: UFSM, 2012. 
QUADROS, Marta Campos de. Tá Ligado?!: Práticas de escuta de jovens urbanos contemporâneos e panoramas sonoros na metrópole, uma pauta para a Educação. 2011.

Tese (Doutorado em Educação). Programa de Pós-Graduação em Educação, Faculdade de Educação, Universidade Federal do Rio Grande do Sul. Porto Alegre: UFRGS, 2011.

SERRANO, José Fernando. Ni lo mismo, ni lo outro: la singularidade de lo juvenil. Nómadas. Santafé de Bogotá, n.16, p. 10-25, abril 2002.

SILVA, Sandra Rúbia da. Eu não vivo sem celular: sociabilidade, consumo, corporalidade e novas práticas nas culturas urbanas. Intexto, Porto Alegre: UFRGS, v. 2, n. 17, p. 1-17, julho/dezembro 2007. Disponível em: < http://seer.ufrgs. br/intexto/article/view/3457/>. Acesso em 20 ago. 2011.

STEINBERG, Shirley R.; KINCHELOE, Joe. Sem Segredos: cultura infantil, saturação de informação e infância pós-moderna. In: STEINBERG, Shirley R.; KINCHELOE, Joe.(org.). Cultural infantil: A construção corporativa da infância. Trad. George Eduardo Jupiassú Brício. Rio de Janeiro: Civilização Brasileira, 2001. p. 9-52.

SKLIAR, Carlos. Os Estudos Surdos em Educação: problematizando a normalidade. In: SKLIAR, Carlos.(org.) Surdez. Um olhar sobre as diferenças. 6ed. Porto Alegre: Mediação, 2012. p. 7-32.

STROBEL, Karin. As imagens do outro sobre a cultura surda. 2 ed. rev. Florianópolis: Ed. da UFSC, 2009.

THOMA, Adriana da S.; GIORDANI, Liliane Ferrari. Percursos de formação: memórias e trajetórias de professores que atuam na educação de surdos. V CIPA - CONGRESSO INTERNACIONAL DE PESQUISA (AUTO)BIOGRÁfICA. Porto Alegre, Brasil, 2012.

WILLIS, Paul. Common Culture: symbolic work at play in the everyday cultures of the young. Buckingham, UK: Open University Press, 1990.

WRIGLEY, O. The politics of deafness. Washington: Gallaudet University Press, 1996.

VITELLI, Celso. Relação entre jovens, consume, estética e shopping centers. In: PINTO. Michele L.; PACHECO, Janie K. (orgs.). Juventude, Consumo e Educação. Porto Alegre, ESPM, 2008. p. 27-43. 


\section{Sites}

ABC FAMILY, <http://beta.abcfamily.go.com/shows/switched-at-birth>. Acesso em 2 nov. 2012.

CULTURA SURDA,<http://culturasurda.net/sobre-o-site/>. Acesso em 25 nov. 2012.

IBGE. Instituto Brasileiro de Geografia e Estatística. Censo Demográfico 2010. Disponível em < http://www.ibge.gov.br/home/estatistica/populacao/censo2010/sinopse.pdf>. Acesso em 2 ago. 2011.

Recebido em 01/10/2012

Aprovado em 15/11/2012 